\title{
Soft Skills and IS/IT Project Management: A Case Study of Nepalese IS/IT Professionals
}

\author{
Rajib Subba \\ King's College \\ Yujesh Maleku \\ King's College \\ Bhanu Shrestha (https://orcid.org/ 0000-0001-9513-2046) \\ King's College
}

\section{ABSTRACT}

There is an increasing focus on managing and executing Information System/Information Technology (IS/IT) projects with geographically and culturally dispersed teams. Best practices, theories, and a body of knowledge on managing projects have been well-established, but there is a limited understanding of Nepal's multi-cultural IS/IT project management dynamics. In this study, we conducted a purposive survey to determine the soft skills that are given significance by the Nepalese IS/IT professionals working in a multicultural environment. The first three preferred essential skills identified by the survey are communication, team building, and leadership skills. In contrast, the respondents perceived trustworthiness and organizational effectiveness as the least essential soft skills for IS/IT projects. Among the emerging soft skills, capacity for analysis and synthesis and critical thinking skills were considered highly essential for IS/IT projects. Work ethic and ability to work in an international context came second and third, respectively. We expect our findings to help Nepali IS/IT project managers understand which soft skills are valued most in their respective workplaces in the various phases of project management.

Keywords: soft skills, multi-cultural IS/IT projects, IS/IT project management, Nepalese IS/IT professionals

\section{Soft Skills and IS/IT Project Management: A Case Study of Nepalese IS/IT Professionals}

A formal meeting between project members generally occurs face-to-face; a project manager brings their team into a meeting room, the team discusses project progress, addresses concerns, and then heads back to their desks. This practice was rampant around the world in an organizational context until the mid-1990s (Apgar, 1998; Moseley, 2021). However, the practice started to change when computer and Internet technologies became more affordable and widespread. Today, geographical or organizational boundaries are no longer a matter of concern for a project manager in a distributed project work environment. Now a manager can initiate a conference call while in transit at Honolulu airport while one team member from the IT group could be in Silicon Valley. Her designer staff could be telecommuting in Milan, and a BPO contractor working on the project could assemble a group of co-workers in an office in suburban Bangalore. A buyer could even be at 
Everest base camp conversing through a satellite phone.

This is a flat world brought closer by the information technology revolution (Friedman, 2007). Ducker (1993) predicted, "commuting to the office is obsolete," and presently, people around the world are telecommuting in large numbers (p. 340). For example, the number of people who work from home has increased by 140\% since 2005 (Simovic, 2021). With the advent of the pandemic, organizations are conducting meetings electronically. The number of Zoom daily meeting participants grew from 10 million in December 2019 to 200 million in March 2020 (Zoom, 2020). Meetings over online platforms like Zoom, Microsoft Team, Cisco Webex, and Google Meet have become everyday occurrences. Today, people are working together from different parts of the world and trying to achieve the same organizational goals by utilizing new information and communication technologies. In these cases, managing a project is a considerable challenge when team members are from diverse cultures and spread around various countries. When managing projects in a face-to-face environment is a challenge, handling distributed project teams is an uphill task for many project managers.

\section{IS/IT Project Scenario in Nepal}

There are nine hundred Information System/Information Technology (IS/IT) companies registered with the Federation of Computer Association of Nepal (Dixit \& Lohani, 2017). Thirty software companies, with human resources, ranging from seven to one thousand, provide offshore development services to international markets (Pandey, 2018). Dixit and Lohani (2017) found that offshore software companies in Nepal hire up to 120 staff and deploy up to six professionals to process offshore projects for countries like the USA, the UK, Canada, India, Australia, Germany, France, Netherlands, Belgium, Switzerland, Poland, Sweden, Russia, New Zealand, Hong Kong, Philippines, Singapore, South Korea, China, Japan, Myanmar, Bhutan, Bangladesh, and Africa.

\section{Significance of the Study}

Though there are numerous studies assessing the importance of soft skills for project management in the IT sector (Jena \& Satpathy, 2017; Snell et al., 2002; Stevenson \& Starkweather, 2010; Strang, 2003; Sukhoos et al., 2005), there has been little research about the importance of soft skills in Nepal's IS/IT sector. This is especially important because, in recent years, the Nepali IS/IT sector has been providing outsourcing services to several international clientele, requiring managers to complete a wide variety of requirements to satisfy client needs. This paper investigates how much cross-cultural IS/IT professionals in Nepal value the soft skills required for meeting those deliverables.

Previous research indicates that understanding others' cultures matters in IS/IT project management. For example, Orlikowski (2002) argues, "Globally distributed software production is shaped and challenged by cultural factors (various nationalities and organizational culture)" (p. 255). Similarly, Yalaho and Nahar (2010), based on their research on the vendors (from India, Nepal, and Russia) and clients (from Finland), found that "understanding the user's cultural dimension and product knowledge is critical for the success of the product" (p. 7). Moreover, "when an information system is designed in one culture and intended for use in another national cultural, gaps may exist" (Shore \& Venkatachalam, 1994, p. 177), indicating why IS/IT companies should value the multicultural dimensions. While the Nepali IS/IT sector is becoming multicultural, with workers and clients from various backgrounds and nationalities, the soft skills associated with project management have not been explored in much detail. Therefore, this article investigates the significance of various soft skills (e.g., communication, team building, leadership) for professionals working in Nepal's IS/IT sector.

The government of Nepal has developed a roadmap called the Digital Nepal Framework that aims to realize Nepal's economic potential in the digital sphere by utilizing disruptive technology and developing human resources in ICT and related sectors, targeting critical skills areas (Digital Nepal Framework, 2019). Similarly, Dixit and Lohani 
(2017) state that Nepali software companies have been exporting business application software, embedded software, as well as web advertisements and mobile applications to multiple foreign countries including the USA, UK, Canada, India, Australia, Netherlands, Thailand and Russia as well as other European and Asian countries. However, there is a dearth of research about which soft skills are valued more in the various phases of project development in the Nepali IS/IT sector. Therefore, our contribution to the project management domain is to identify which soft skills are highly prioritized by individuals working in Nepal's IS/IT sector in the initiating, planning, executing, controlling, and closing stages of the project management cycle. We have proposed a framework that may guide IS/IT professionals to use different soft skills based on the project management (PM) cycle phases. For example, communication skills may be needed during initiating, executing, controlling, and closing phases. The proposed adapted framework (see Table 8) helps IS/IT project managers not only in Nepal but across the globe because the adapted framework includes contemporary and emerging soft skills relevant to IS/IT projects.

\section{Research Framework}

Diverse clients such as small businesses, corporations, and government agencies demand more expertise in IS/IT project management. Therefore, this exploratory research study intends to identify which soft skills are perceived as essential for IS/IT projects in multicultural settings by Nepalese IS/IT professionals, including project managers and developers involved in the projects led by those managers. In addition, it aims to understand which soft skills are perceived as essential for the various stages of the project management life cycle.

The analytical framework used in this study is Sukhoos et al. 's (2005) framework on soft skills for project management and includes emerging soft skills, as discussed by ColomoPalacias (2012), Mtsweni (2016), and Florea and Stray (2018). A survey was conducted among forty Nepalese IS/IT professionals working in Nepal, the USA, and Australia. We found this to be a multicultural environment as professionals from different countries were working together. Information technology provides a level playing field for companies in developing countries like Nepal, receiving business process outsourcing opportunities in recent years (Dixit \& Lohani, 2017). Such opportunities are creating a multicultural environment in the companies that are working for international clients. Nepal's multicultural environment can be attributed to relatively cheap human resource costs, which have allowed Nepal to become an outsourcing hub with Nepali companies providing IT services to the US, Canada, Australia, and some European nations (Prasain, 2018).

\section{Soft Skills}

Conventionally, project managers link their actions with organizational goals and control activities to then execute according to project goals (Lester, 2007; Project Management Institute, 2017; Shenhar \& Dvir, 2007). This mechanistic concept assumes that future outcomes can be predicted accurately based on current information and actions. The project management tools and techniques are quantitative which are developed to determine the predetermined objectives in a pre-defined manner. This is described as hard skills in the project management literature (Lewis \& Boucher, 2019). As per Ravindranath (2016), the technical knowledge linked to a firm's activities, businesses, and customers is referred to as hard skills, which include the capacity to engage computer protocols, financial procedures, modeling applications, and other similar skills which are predetermined to be used in specific situations. Because they are based on certified learning techniques, these abilities are reasonably easy to examine and assess. However, the other side of this skill paradigm is the ability to be people-centric, which is described as soft skills (Mateo, 2017). As defined by Ravindranath (2016), soft skills are an art, a process of managing and working with people, and in the context of businesses, defining an atmosphere to deliver high-quality products within budget and at the right time while satisfying customer needs. Soft skills can be described as an art acquired through experience and are concerned with managing and working with people and creating a conducive environment for the project team to 
deliver high-quality products. The hard-skillsfocused managers tend to be "mechanistic and emphasize efficient, expert-led delivery, control against predetermined goals and an interest in underlying structure" and soft-skills focused managers "emphasize learning, participation, the facilitated exploration of projects, and typically demonstrate an interest in underlying social process" (Pollack, 2007, p. 45).

Essentially, hard skills are technical and encompass the dimensions like processes, tools, and techniques. However, focusing solely on hard skills for project management is illsuited to address emerging challenges (Sukhoo et al., 2005). As remote working becomes the new normal, managers need "people skills." Magano et al. (2020) state that the newer employees of generation $Z$ categorize the following as soft skills that are vital in project management: personality, emotional intelligence, resilience, communication, time management, teamwork, leadership, troubleshooting, conflict management, autonomy, authority, decision-making, customer relationship, analytical thinking, use of technologies, delegation, and creativity. Hard skills remain the traditional focus of IT project management methodologies (Adam, 2016; Awan et al., 2015; Sukhoo et al., 2005). Early literature on project management focuses on the hard skills deemed necessary for managing projects, relegating soft skills to the background, and emphasizes the process and tools more than human relations and thought (Pant \& Baroudi, 2006). However, things are changing for project managers who cannot depend only on the proximity of control but must use skills other than hard skills to make their project a success. Against this background, the question arises of what soft skills a project manager may possess while handling project work. Table 1 presents the classification of soft skills based on previous research.
Table 1

Classification of Soft Skills

\begin{tabular}{|cl|l|}
\hline Types of Soft Skills & Researcher \\
\hline & Communication & Belzer (2004) \\
$\circ$ & Skills & \\
$\circ$ & Teamwork & \\
$\circ$ & Presentation Skills & \\
$\circ$ & Selling & \\
$\circ$ & Running Meetings & \\
$\circ$ & Problem Solving & \\
$\circ$ & Customer Service & \\
$\circ$ & Communication & Moreira (2004, as \\
& Skills & cited in \\
$\circ$ & Team Building Skills & Sukhoo et al., \\
$\circ$ & Leadership Skills & 2005) \\
$\circ$ & Organizational & \\
& Effectiveness & \\
$\circ$ & Flexibility and Skills & \\
$\circ$ & Problem Solving and & \\
& Decision Making & \\
$\circ$ & Trustworthiness & \\
$\circ$ & Communication & Mantel et al. \\
& Skills & Team Building \\
$\circ$ & Leadership & \\
\hline & Organizational Skills & \\
\hline
\end{tabular}

As evidenced in Table 1, communication skills, leadership skills, and team building are common to all three research papers.

With the advent of globalization, extended spans of control, and advanced communication technology (Avolio et al., 2001), project managers are frequently tasked with working with employees in remote locations. In 2008, according to a report by the Gartner Group, a research firm that studies the global IT industry, 41 million corporate employees worked in distributed settings for at least one day per week (Gartner Group, 2008, as cited in Koehne et al., 2012). Such scenarios become complex when organizations use sophisticated information systems, such as supply-chain management, enterprise resource planning, and customer relationship management systems. These cross-functional enterprise systems can fuel significant organizational transformations, which significantly increase the complexity of their implementation (Buingi et al., 1999; Markus \& Tanis, 2000).

Managing projects successfully requires a mixture of skills, including interpersonal ability, technical competencies, cognitive aptitude, and the capability to understand the situation and people and then dynamically integrate 
appropriate leadership behaviors (Strang, 2003). In this context, the project manager's job would become demanding, complex, and varied, requiring juggling several issues concurrently (Pant \& Baroudi, 2006). Ronald and Tamara (2018) state that in their study of 78 project managers from Germany with different industries, including IT, only $2.5 \%$ of the companies completed their projects. Most of the projects failed due to the exceedance of time $(60 \%)$ or communication breakdowns (57\%). Also, $39 \%$ failed due to a lack of planning, resources, and activities. In addition, project managers often fail due to a lack of skills such as understanding the corporate culture, recognizing the dynamics between individuals they are dealing with, and the ability to communicate in a manner to bring different stakeholders to a joint agreement regarding success criteria for a project's outcome (Stevenson \& Starkweather, 2010).

Further investigation identified significant soft skills dimensions for project management. According to Belzer (2004), these include, amongst others, communication skills, organizational effectiveness, team-building skills, flexibility and creativity skills, problemsolving and decision-making skills, trustworthiness, and leadership skills. Moreira (2004, as cited in Sukhoo et al., 2005) identified eight soft skills: teamwork, communication skills, presentation skills, selling, running meetings, leadership, problem-solving, and customer service. Mantel et al. (2004) categorized skills into six areas: communication, organizational, team building, leadership, coping, and technological skills that project managers use.

Three important skills that were found to be overlapped across all three research papers that were investigated are leadership skills, communication skills, and team-building skills (see Table 1). It is imperative for project managers to possess fluency in their communication skills. According to the Project Management Institute (2017), project managers spend $90 \%$ of their time communicating as they need to understand the perspectives of all the various stakeholders. Leadership skills become more salient when managing geographically distributed teams with several issues like culture, inter-organizational issues, lack of faceto-face situations, and distance. In these cases, a leader could be managing teams located across the globe.

Sukhoo et al. (2005) suggested the soft skills attributes of a global IS/IT project manager requires a high level of activation during the different phases of a project (see Table 2). This compilation of soft skills is expected to help the project managers mainly involved in global IS development projects to integrate soft skills in existing and emerging software project management methodologies.

\section{Table 2}

\section{Soft Skills Activation During PM Phases}

\begin{tabular}{|l|l|l|l|l|l|}
\hline \multirow{2}{*}{ Soft Skills } & \multicolumn{5}{|c|}{ Project Management Phases } \\
\cline { 2 - 6 } & Initiating & Planning & Executing & Controlling & Closing \\
\hline $\begin{array}{l}\text { Communication } \\
\text { Skills }\end{array}$ & & & & & \\
\hline Team Building & & & & & \\
\hline $\begin{array}{l}\text { Flexibility and } \\
\text { Creativity }\end{array}$ & & & & & \\
\hline Leadership & & & & & \\
\hline $\begin{array}{l}\text { Organizational } \\
\text { Effectiveness }\end{array}$ & & & & & \\
\hline $\begin{array}{l}\text { Stress } \\
\text { Management }\end{array}$ & & & & & \\
\hline Time Management & & & & & \\
\hline $\begin{array}{l}\text { Change } \\
\text { Management }\end{array}$ & & & & & \\
\hline Trustworthiness & & & & & \\
\hline $\begin{array}{l}\text { Conflict } \\
\text { Management }\end{array}$ & & & & & \\
\hline
\end{tabular}

Note. Adapted from "Accommodating Soft Skills in Software Project Management" by Sukhoo, A., Barnard, A., Eloff, M. M., Van der Poll, J. A., \& Motah, M.,2005, Issues in Information Science and Information Technology, 2, 699700. https://doi.org/10.28945/860. The grey boxes reflect the soft skills deemed most relevant in the corresponding project management phase by Sukhoo's et al.'s (2005) research.

According to Table 2, almost all soft skills listed by Sukhoo et al. (2005) were considered important during the executing phase. Communication skills were prioritized more after the executing phase, while flexibility and creativity were valued in the initiating and planning phase. Similarly, during the closing stage, it was found that the communication skills were valued more than other soft skills being considered. While specific traditional skills, considered as soft skills, were discussed by Sukhoo et al. (2005), recent research has mentioned "emerging soft skills," contemporary skills that are gaining significance and increasing in relevance in today's work culture. Recently, Colomo-Palacias (2012), Mtsweni 
(2016), and Florea and Stray (2018) suggested specific emerging soft skills, such as the ability to work in an international context, an understanding of other cultures and customs, an ability to work under pressure, and a strong work ethic (Table 3).

Table 3

Classification of Emerging Soft Skills

\begin{tabular}{|c|c|}
\hline Types of Emerging Soft Skills & Researchers \\
\hline $\begin{array}{ll}\text { - } & \text { Capacity for analysis and } \\
\text { - } & \text { synthesis } \\
\text { Ability to work on an } \\
\text { interdisciplinary team } \\
\text { - Ability to work in an international } \\
\text { - } \quad \text { Entext } \\
\text { - Unical commitment } \\
\text { anderstanding of other cultures } \\
\text { and customs } \\
\text { Quality Concern }\end{array}$ & $\begin{array}{l}\text { Colomo-Palacias } \\
\text { (2012) }\end{array}$ \\
\hline $\begin{array}{ll}- & \text { Critical Thinking } \\
& \text { Personal Integrity }\end{array}$ & Mtsweni (2016) \\
\hline $\begin{array}{ll}- & \text { Work ethic } \\
- & \text { Critical thinking } \\
- & \text { Detail-oriented } \\
\text { - } & \text { Quality-oriented }\end{array}$ & Florea \& Stray (2018) \\
\hline
\end{tabular}

Organizations are looking for more soft skills in IS/IT project managers. Global projects have multi-cultural issues which influence the success of those projects. Project organizations are increasingly dealing with global multi-cultural teams, which often generate frustrating project management experiences related ethical dilemmas such as employee management in multicultural workplaces and special treatment (Walker \& Lloyd-Walker, 2014). These are mostly due to the lack of soft skills, such as the ability to work in an interdisciplinary team and in an international context. Also, cultural differences create substantial obstacles to effective teamwork, but these may be subtle and difficult to recognize until significant damage has already been done (Brett et al., 2006). Similarly, communication barriers are magnified in global teams when they work via virtual technologies (Anantatmula \& Thomas, 2010). Therefore, multi-cultural issues must be tackled before they create a source of conflict for the project (Hinds \& Bailey, 2003).

\section{Methodology}

We conducted a survey among

Nepalese IS/IT professionals using an exploratory research design and the purposive- sampling method. The purposive-sampling technique is most appropriate when participants are deliberately chosen due to the qualities that are possessed by the participants (Etikan et al., 2016). In this study, 40 IS/IT professionals working in IT/Business Process Outsourcing (BPO) projects in Nepal, the USA and Australia were approached. Survey participants were all working professionals who had been working in IT/BPO for more than five years. Participants were selected due to their knowledge or experience and were proficient and wellinformed with the phenomenon of interest (Bernard, 2002; Cresswell \& Clark, 2011). The survey was anonymous, and no personal data was collected. The questionnaires were prepared to meet the research objectives of understanding which soft skills are needed for IS/IT project management with an additional focus on identifying which soft skills are useful for the five stages of project management.

The questionnaires were divided into two sections. The first section focused on the need for soft skills and the importance of soft skills (from Table 1) in different stages of the project management cycle. The initial portion of the questionnaire asked the respondents to choose whether they consider hard skills, soft skills, or both as the core competencies required for IS/IT projects in multicultural organizations. Respondents were also asked, "Do you think project managers lack the soft skills needed for IS/IT projects in multicultural organizations?"

The second section focused on the emerging skills mentioned in Table 3 and the respondents' preference for these at different stages of the project management cycle. Participants were given a list of the soft skills from Table 1 as a multiple-choice question to determine which soft skills they believed to be essential for IS/IT projects. The respondents were also asked to select in which phase of the project management cycle each of the skills could be deemed to be most appropriate. In the second section of the questionnaire, the respondents were given the multiple-choice multiple select options to choose the most appropriate emerging skills (see Table 3 ) for each of the different stages of the project management cycle. 


\section{Analysis and Discussion}

For the study, the survey data was used to generate relevant charts that enumerated the information collected from the study, which was then further discussed to create valuable insights.

Seventy-seven percent of the respondents said project managers lack soft skills. This signifies that most project managers need to update their soft skills. This also signifies that the IS/IT project managers must have an ability to see beyond technical competences and focus more on polishing the soft skills needed. Communication, teambuilding, and leadership skills were the first three preferred essential skills for IS/IT projects based on the respondents' choices. Trustworthiness and organizational effectiveness were perceived to be the least essential soft skills for IS/IT projects by the respondents (see Table 4).

\section{Table 4}

Soft Skills Preferred (in \%)

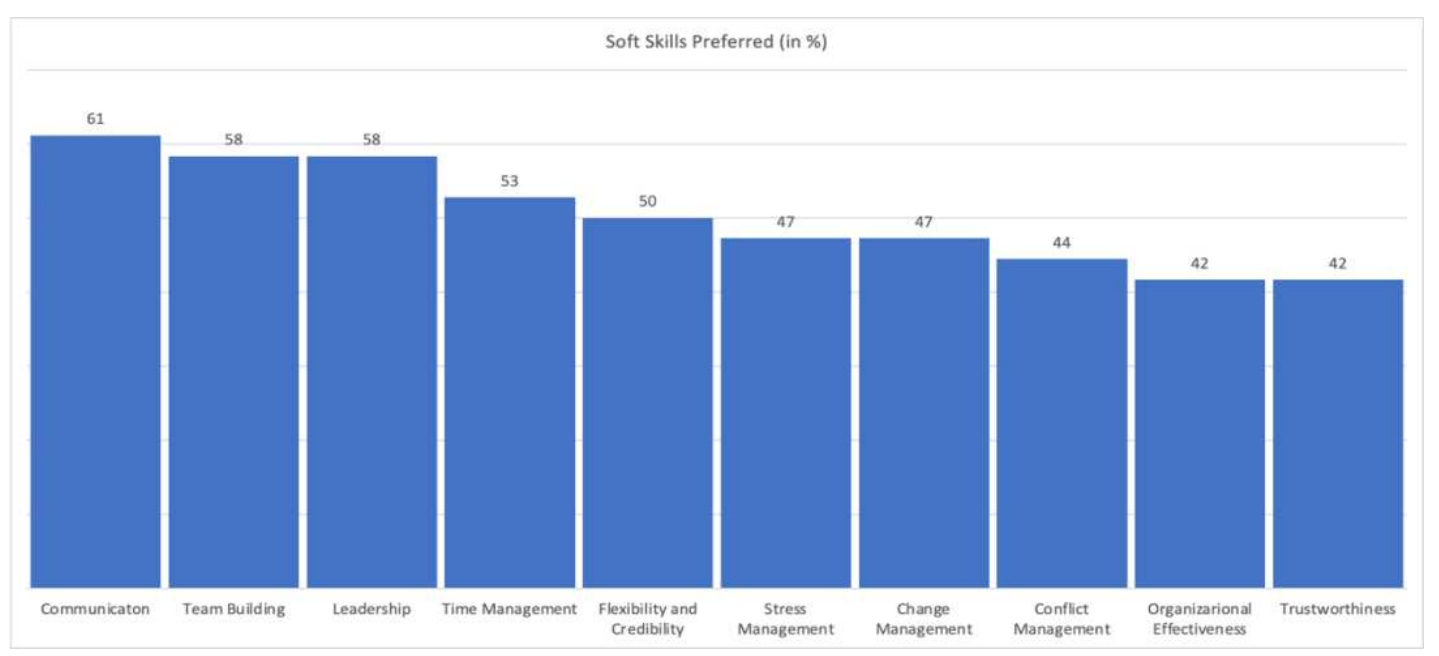

Unlike Sukhoo's (2005) framework regarding activation of certain soft skills during the project life cycle, our respondents selected that all skills should be present in all phases. The reason could be that respondents come from various backgrounds and may not be responsible for software development as defined in Sukhoo's (2005) framework. Based on the data, communication and team-building skills are mostly preferred during the initiation phase. Responses also indicate that all the other soft skills mentioned in Sukhoo's (2005) framework are valued the most during the execution phase. Change management and team-building skills were the least important skills ranked during the closing stage, while conflict management was the most preferred skill during this stage (see Table 5). 
Table 5

Soft Skills Preference in Project Management

Phases (in \%)

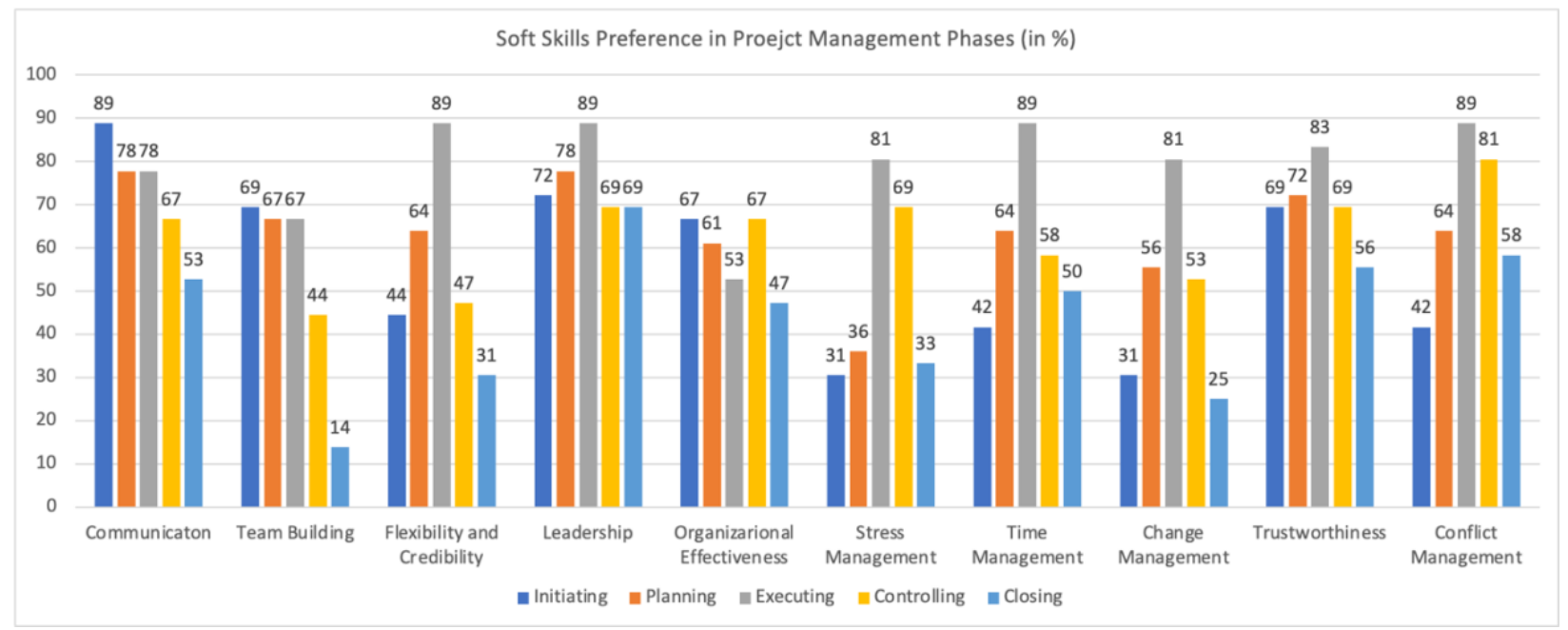

Among the emerging soft skills, capacity for analysis and synthesis and critical thinking skills were considered highly essential for IS/IT project, whereas work ethic and ability to work in an international context came second and third, respectively.

Table 6

Emerging Soft Skills preferred (in \%)

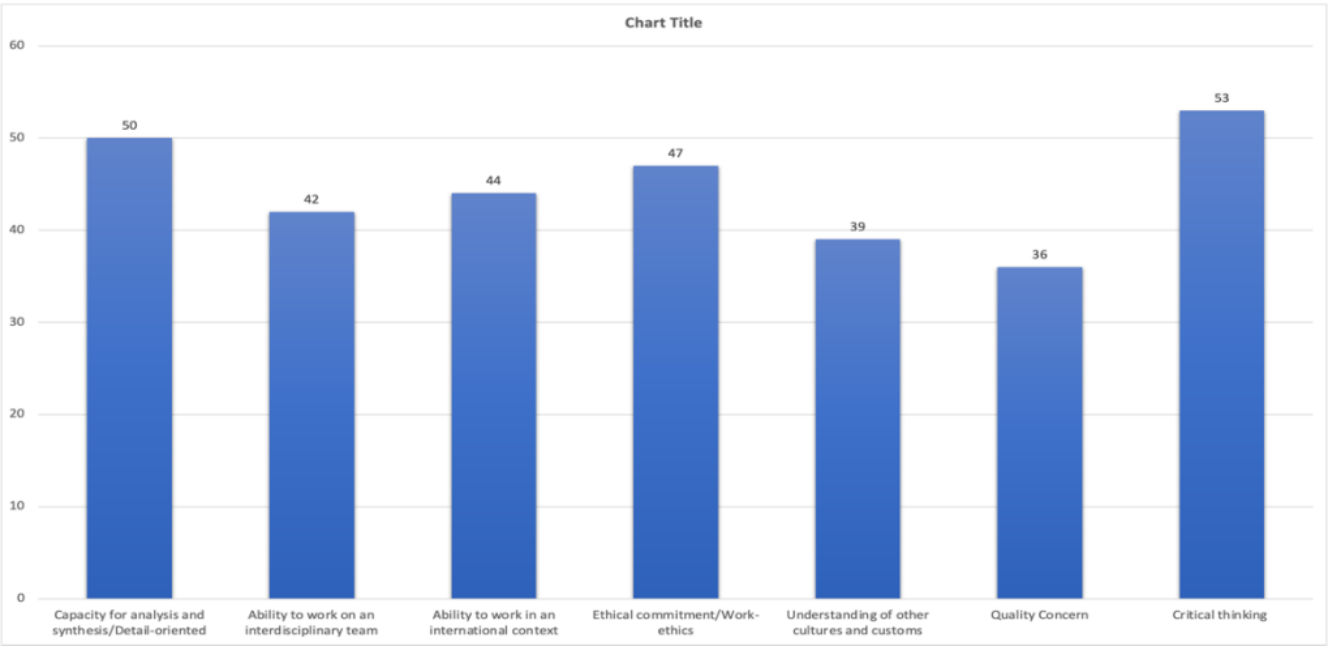

Ninety-two percent of the respondents mentioned that they considered the soft skill, "ability to work in an interdisciplinary team," as most important during the executing phases, highlighting the value of the skill while executing tasks in a multicultural IS/IT project. In addition, this preference indicates that multicultural teams have professionals from 
various backgrounds and a lack of experience managing international teams would negatively impact the project. However, respondents deemed this skill least preferred during the closing phase. Table 7 displays the preferences in each project management phase for the different emerging soft skills.

\section{Table 7}

Emerging Soft Skills and Project Management Phases Preference (in \%)

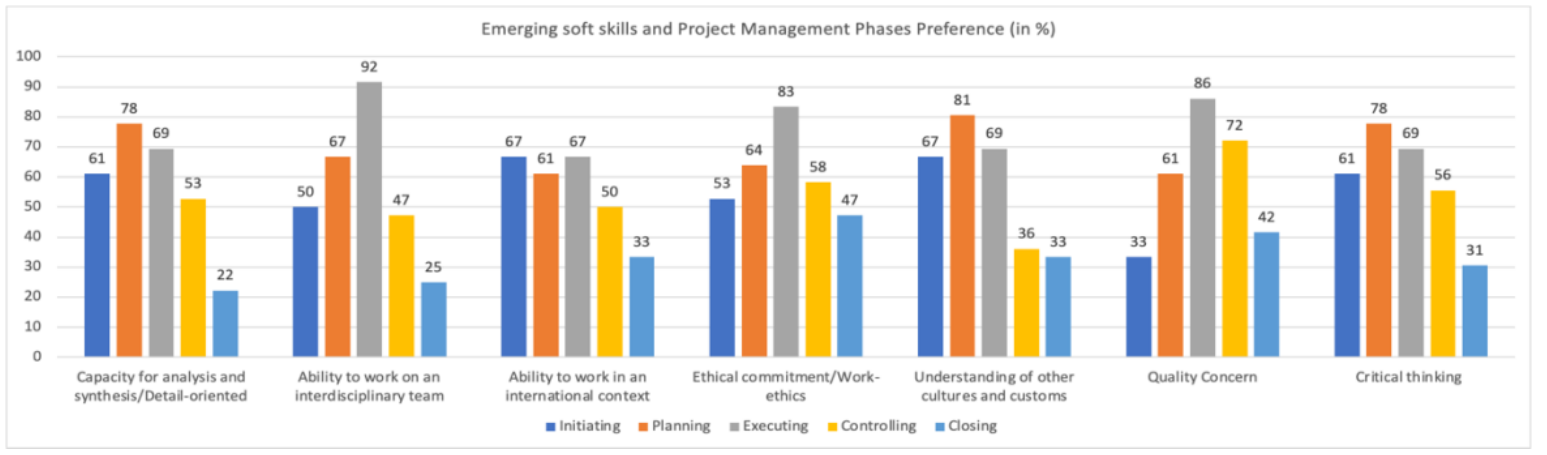

As per the respondents' preferences of the emerging skills, the data indicate that the ability to work on an interdisciplinary team, ethical commitment, quality concern and the ability to work in an international context were considered the most essential during the executing phase while the remaining three skills were preferred the most during the planning phase.

\section{Integrating Traditional Soft Skills and Emerging Soft Skills}

The soft skill activation framework for different phases of IS/IT projects adapted for the Nepalese context based on the analysis and discussion presented above are shown in Table 8. This table also includes the most preferred emerging soft skills during different project management phases. This extended framework intends to help project managers define which skills to activate during which phase of the projects in Nepal.
Table 8

Soft Skills Activation During PM Phases

\begin{tabular}{|l|l|l|l|l|l|}
\hline \multicolumn{1}{|c|}{ Soft Skills } & \multicolumn{4}{|c|}{ Project Management Phases } \\
\cline { 2 - 6 } & Initiating & $\begin{array}{l}\text { Plan- } \\
\text { ning }\end{array}$ & $\begin{array}{l}\text { Execut } \\
\text {-ing }\end{array}$ & $\begin{array}{l}\text { Control- } \\
\text { ling }\end{array}$ & Closing \\
\hline $\begin{array}{l}\text { Communication } \\
\text { Skills }\end{array}$ & & & & & \\
\hline Team Building & & & & & \\
\hline $\begin{array}{l}\text { Flexibility and } \\
\text { Creativity }\end{array}$ & & & & & \\
\hline Leadership & & & & & \\
\hline $\begin{array}{l}\text { Organizational } \\
\text { Effectiveness }\end{array}$ & & & & & \\
\hline Stress Management & & & & & \\
\hline Time Management & & & & & \\
\hline $\begin{array}{l}\text { Change } \\
\text { Management }\end{array}$ & & & & & \\
\hline Trustworthiness & & & & & \\
\hline $\begin{array}{l}\text { Conflict } \\
\text { Management }\end{array}$ & & & & & \\
\hline $\begin{array}{l}\text { Capacity for analysis } \\
\text { and synthesis/Detail- } \\
\text { oriented }\end{array}$ & & & & & \\
\hline $\begin{array}{l}\text { Ability to work on an } \\
\text { interdisciplinary team }\end{array}$ & & & & & \\
\hline $\begin{array}{l}\text { Ability to work in an } \\
\text { international context }\end{array}$ & & & & & \\
\hline $\begin{array}{l}\text { Ethical } \\
\text { commitment/Work- } \\
\text { ethics }\end{array}$ & & & & & \\
\hline $\begin{array}{l}\text { Understanding of } \\
\text { other cultures and } \\
\text { customs }\end{array}$ & & & & & \\
\hline Quality Concern & & & & \\
\hline Critical thinking & & & & \\
\hline
\end{tabular}

Note: The grey color indicates the soft skills preference according to Sukho et al. (2005)'s finding while the orange highlights indicate our findings. 


\section{Reflections}

The fact that $77 \%$ of the respondents said project managers lack soft skills suggests that most project managers need to update their soft skills. This also signifies that the IS/IT project managers must have an ability to see beyond technical competences and focus more on polishing the soft skills needed.

The selection of appropriate soft skills during different phases of the project management cycle was found to deviate from Sukhoo's (2005) framework of activating soft skills. This could be because respondents come from various backgrounds and may not be responsible for software development as defined in Sukhoo's (2005) framework. Elements of Sukhoo's (2005) framework are drawn from various research, including University of Arkansas which was conducted by Teeter et al. (1999) on the data collected from individuals involved in IT companies. However, the research participants were generalists and managers who worked in 16 companies in Arkansas. This study found participants consider leadership and diversification (different cultures) less desired skills.

However, the multicultural workforce targeted for this survey's response, which reflects the dynamic workforce of the present day, might have also resulted in a difference from Sukhoo's (2005) framework. The respondents for our survey worked in various IS/IT fields, including quality assurance, quality control, auditing, debugging, DevOps, and IT admins. This might have caused the result to deviate from Sukhoo's (2005) framework, which is why emerging soft skills can be assumed to be more critical. For example, for quality control, communication skills might also be essential in earlier phases of the project management cycle, while emerging skills like quality concern could be more helpful in different phases.

An overwhelming majority of the respondents mentioned that they considered the soft skill, "the ability to work in an interdisciplinary team" as the most important during the execution phases. Modern workforces have professionals from different disciplines working together who have experience working in various fields. Therefore, we can infer that the managers need to manage interdisciplinary teams in the current workforce environment.

\section{Limitations and Future Research}

In this research study, we identified two limitations. The first limitation is the sample size. Responses from only 40 participants were collected. A larger sample size would have been more representative of the diverse population from which it was drawn.

While the respondents were not explicitly asked about their work experience or if they or a project manager they had worked with were from an IS/IT background, respondents were carefully chosen to provide selective sampling. Most of the respondents were working IT professionals with varied working experiences in local as well as multinational companies. To minimize the researchers' bias on the selection of respondents, researchers opted for IS/IT professionals not only working in Nepal but also in the USA and Australia.

One issue that deserves future research is the exploration of the experience of different time zone workers and their need for soft skills. The modern realities of working in different time zones could bring about more insights about a different set of challenges and soft skills required to work effectively. As more people have been working alone during the pandemic or in freelancing work as part of distributed remote team, studying personal and work life balance, an ability to have visibility of work, adjusting to varying time zones of partners, an ability to retain motivation to work as a solo teammate away from rest of the team and managers developing restraint from continuous interruption may be of interest but was not considered for this research (Koehne et al., 2012).

Additional research could also focus explicitly on Nepalese IS/IT project managers to understand their activation of soft skills at different phases. Moreover, further research is needed to understand the interaction of leadership style, team building, and soft skills, as leadership does not exist without a team.

Moreover, future research should focus on the usage of different project management tools and the capability of using those tools effectively as part of the soft skills required in the IT industry. Future studies could also have more respondents from IT companies with different employee sizes to understand if the company culture of companies of different sizes might 
cause a difference in priority of the soft skills that are valued by IT professionals.

\section{Conclusion}

A major contribution of this research is its findings that Nepalese IS/IT professionals view communication, team building, and leadership as essential for managing offshore projects. However, their preferences for communication and team-building skills during the initiation phase of project management suggest that Sukhoo et al.'s (2005) framework should be adapted. Similarly, adding emerging skills to the framework is pertinent with the rise of telecommunication due to the pandemic. We expect our findings to help Nepali IS/IT project managers understand which soft skills are valued most in their workplace to improve those skills. Additionally, we hope our findings will show IS/IT companies which soft skills are preferred so that they can target those skills while making hiring for managerial positions. Skills in managing relationships are critical to achieving stakeholder satisfaction through all project stages. Relationship skills complement the effectiveness of hard (technical) skills because project outcomes are achieved through people, using their knowledge and creativity, not through the mere use of techniques or hardware. Creating the right relationships with team members and other stakeholders is one of the biggest challenges for project managers which requires them to cultivate a mix of emerging and traditional soft skills.

\section{References}

Adams, H. (2016). A different approach to project management: The use of soft skills. [Master's Thesis, Harrisburg University of Science and Technology]. Digital Commons @ Harrisburg University. http://digitalcommons.harrisburgu.edu/pmgt dan $\underline{\mathrm{dt} / 2}$

Apgar, M. (1998, May 1). The alternative workplace: Changing where and how people work. Harvard Business Review.

https://hbr.org/1998/05/the-alternativeworkplace-changing-where-and-how-peoplework
Anantatmula, V., \& Thomas, M. (2010). Managing global projects: A structured approach for better performance. Project Management Journal, 41(2), 60-72.

Awan M. H., Ahmed K., \& Zulqarnain W. (2015). Impact of project manager's soft leadership skills on project success. Journal of Poverty, Investment and Development, 8, 27-47.

Belzer, K. (2004, August 7). Project management: Still more art than science [Unpublished manuscript].

http://www.egrupos.net/cgibin/eGruposDMime.cgi?K9U7J9W7U7xumopxC nhuMyqjdkuymCYTUVCvthCnogdyglhhyCXUQkfb7

Bernard, H. R. (2002). Research methods in anthropology: Qualitative and quantitative approaches (3rd ed.). AltaMira Press.

Bjorkman, I., \& Schaap, A. (1994). Outsiders in the middle kingdom: Expatriate managers in Chinese-Western joint ventures. European Journal of Management, 12(2), 147-53.

Brett, J. K., Behfar, K., \& Kern, M. C. (2006). Managing multicultural teams. Harvard Business Review https://hbr.org/2006/11/managingmulticultural-teams

Colomo-Palacios, R., Casado-Lumbreras, C., Soto-Acosta, P., J. García-Peñalvo, F., TovarCaro, E. (2013). Competence gaps in software personnel: A multi-organizational study. Computers in Human Behavior, 29 (2), 456-461. https://doi.org/10.1016/j.chb.2012.04.021

Cresswell, J. W., \& Clark, V. L. P. (2011). Designing and conducting mixed method research (2nd ed.). SAGE.

Dixit, K. M., \& Lohani, R.D. (2017). Computerization in Nepal: State of hardware and software business. Institute for Social and Environmental Transition (ISET)-Nepal.

Drucker, P. F. (2011). The ecological vision: Reflections on the American condition ( $1^{\text {st }} \mathrm{ed}$.). Routledge. https://doi.org/10.4324/9781351294560

Etikan, I., Musa, S. A., \& Alkassim, R. S. (2016). Comparison of convenience sampling and purposive sampling. American Journal of 
Theoretical and Applied Statistics, 5(1), 1 4. https://doi.org/10.11648/i.ajtas.20160501.11

Florea R., \& Stray, V. (2018). Software tester, we want to hire you! An analysis of the demand for soft skills. In Garbajosa J., Wang X., Aguiar

A. (Eds), Agile processes in software engineering and extreme programming. Springer, Cham. https://doi.org/10.1007/978-3319-91602-6 4

Frame, J. D. (1987). Managing projects in organizations. Jossey Bass.

Friedman, T. L. (2005). The world is flat: A brief history of the twenty-first century. Farrar, Straus and Giroux.

Hinds, P. J., \& Bailey, D. E. (2003). Out of sight, out of sync: Understanding conflict in distributed teams. Organization Science, 14(6), 615-32.

Jena, A., \& Satpathy, S. S. (2017). Importance of soft skills in project management.

International Journal of Scientific Research and Management, 5(7), 6173-6180.

https://journals.indexcopernicus.com/api/file/vie wByFileld/284621.pdf

Koehne, B., Shih, P. C., \& Olson, J. S. (2012, February). Remote and alone: Coping with being the remote member on the team [Conference proceedings]. ACM 2012 Conference on Computer Supported Cooperative Work (12571266).

Lester, A. (2007). Project management. A. Lester, (Ed.). In project management, planning and control (5th ed.). Butterworth-Heinemann. https://doi.org/10.1016/B978-0750669566/50005-8.

Lewis, Y. R. \& Boucher, L. (2012). PM-people management or project management? [Paper presentation]. PMI® Global Congress 2012. Vancouver, British Columbia, Canada. Project Management Institute.

Magano, J., Silva, C. S., Figueiredo, C., Vitória, A., Nogueira, T., \& Pimenta Dinis, M. A. (2020). Generation Z: Fitting project management soft skills competencies-A mixed-method approach. Education Sciences, 10 (7), 187. https://doi.org/10.3390/educsci10070187

Makilouko, M. (2004). Coping with multi-cultural projects: The leadership style of Finnish project managers. International Journal of Project Management, 22(5), 387-396.

Mantel, S. J., Meredith J. R., Shafer, S. M., \& Sutton, N. M. (2004). Core concepts: Project management in practice (with $C D$ ) (2nd ed.). John Wiley and Sons.

Mateo, J. R. S. Cristóbal., de Navamuel, E. D. R., \& Villa, M. A. G. (2017). Are project managers ready for the 21 st challenges? A review of problem structuring methods for decision support. International Journal of Information Systems and Project Management, 5(2), 43-56.

Moreira, P., (2004). Soft skills for IT professionals.

http://www.certmag.com/issues/jan01/dept tech careers.cfm

Moseley, S. (n.d.). From evolution to revolution: How meetings have changed in 25 Years. https://highfive.com/blog/how-meetings-havechanged-in-25-years

Mtsweni, E. S., Hörne, T., \& van der Poll, J. A. (2016). Soft skills for software project team members. International Journal of Computer Theory and Engineering, 8(2), 150-155. https://doi.org/10.7763/IJCTE.2016.V8.1035

Orlikowski, W. J. (2002). Knowing in practice: Enacting a collective capability in distributed organizing. Organization Science, 13(3), 249273. https://doi.org/10.1287/orsc.13.3.249.2776

Pandey, S. G. (2018). Employment potential in IT industry in Nepal. Federation of Computer Association of Nepal, Kathmandu.

Pant, I., \& Baroudi, B., (2008). Project management education: The human skills imperative. International Journal of Project Management, 26(2), 124-128.

Pollack, J (2007). The changing paradigms of project management. International Journal of Project Management, 25, 266-274.

Prasain, K. (2018, July 30). Nepal's outsourcing firms in hot demand.

https://kathmandupost.com/money/2018/07/30/n epals-outsourcing-firms-in-hot-demand

Project Management Institute. (2017). A guide to the project management body of knowledge (PMBOK guide) (6th ed.). 
https://www.pmi.org/pmbok-guidestandards/foundational/PMBOK

Ravindranath, S. (2017). Soft skills in project management: A review. IUP Journal of Soft Skills, 10(4), 16-25.

https://ssrn.com/abstract $=3079336$

Ronald, B., \& Tamara, H. (2018). Case study: Re-visiting the roles of project management maturity and organizational culture for perceived performance - A replication based on German data. Advances in Management. 11(4), 13-30. https://www.proquest.com/scholarlyjournals/case-study-re-visiting-roles-projectmanagement/docview/2139486586/se2?accountid $=158986$

Roy, V., Bernier, C., \& Le'veille', L. (2006). The high wire balancing act of the IF project director: Database for advanced information systems. ACM SIGMIS Database: the DATABASE for Advances in Information Systems, 37(1), 8-39. https://doi.org/10.1145/1120501.1120504

Shenhar, A. J., \& Dvir, D. (2007). Reinventing project management: The diamond approach to successful growth and innovation. Harvard Business Review Press.

Shore, B., \& Venkatachalam, V. (1994). Prototyping: A metaphor for cross-cultural transfer and implementation of IS applications. Information \& Management 27, 175-184. https://doi.org/10.1016/0378-7206(94)90045-0

Snell, S., Snell-Siddle, C., \& Whitehouse, D. (2002, July). Soft or hard boiled: Relevance of soft skills for IS professionals [Conference proceedings]. The 15th Annual Conference of the National Advisory Committee on Computing Qualifications, 403-408.

https://www.citrenz.ac.nz/conferences/2002/pap ers/snell403.pdf
Stevenson, D. H., \& Starkweather, J. A. (2010). PM critical competency index: IT execs prefer soft skills. International Journal of Project Management, 28(7), 663-671. https://doi.org/10.1016/j.ijproman.2009.11.008

Strang, K. D., (2003, September). Achieving organizational learning across projects [Paper proceedings]. PMI North America global congress, 2003, Baltimore, USA.

Sukhoo, A., Barnard, A., Eloff, M. M., Van der Poll, J. A., \& Motah, M. (2005). Accommodating soft skills in software project management. E. B. Cohen (Ed.). Issues in Informing Science and Information Technology. 2, 691-703. https://doi.org/10.28945/860

Teeter, T. A., Bailey, J. L., Cherepski, D. D., Faucet, J. H., Robert J., Jovanovic, N. S., Tschumi, P., Walker, J. T., \& Watson, G. B. (1999). Preparing for a new century: Information technology workforce needs. Arkansas University Little Rock.

Turner, J. R. (1999). The handbook of projectbased management: Improving the processes for achieving strategic objectives. McGraw-Hill.

Walker, D., \& Lloyd-Walker, B. (2014). Clientside project management capabilities: Dealing with ethical dilemmas. International Journal of Managing Projects in Business, 7(4), 566-589.

Yalaho, A. \& Nahar, N. (2010). Key success factors for managing offshore outsourcing of software production using the ICT-supported unified process model: A case experience from Finland, India, Nepal and Russia [Conference proceedings]. PICMET 2010 conference on Technology Management for Global Economic Growth (1-14). 